\title{
Can a Systemic-Phenomenological Teacher Professional Development Program Enhance Awareness of Intuitions and Serve Pedagogical Tact?
}

\author{
Gerbert Sipman $^{1,2}$ (D) Jürg Thölke ${ }^{3} \cdot$ Rob Martens $^{4} \cdot$ Susan McKenney $^{2}$
}

Accepted: 23 February 2021 / Published online: 2 April 2021

(C) The Author(s) 2021

\begin{abstract}
In all levels of education, teachers' abilities to deal with complex classroom situations in split-seconds concerns pedagogical tact, a crucial quality which relies, in part, on intuition. Developing the ability to appropriately handle the complexity of classroom situations requires a systemic approach. This study aimed to explore the experiences in and effects of a systemic-phenomenological professional development program for enhancing teacher abilities to handle complex (classroom) situations through conscious attention for intuition. In the present study, 64 teachers from primary, secondary, and higher education participated in a 12 week professional development program featuring systemic-phenomenological exercises, such as meditations and embodied simulations. By increasing understanding of the complexity of social systems and sensitizing awareness of intuitive signals, the program aimed to improve teachers' use of intuition, and through that, their handling of classroom situations. Data were gathered through participant reflection $\operatorname{logs}$ and focus group discussions, which were analysed both deductively and inductively. The findings suggest that the program helped heighten teacher awareness of intuitions, and individual awareness in the classroom, yielding positive effects on teacher abilities to take appropriate split-second action in complex classroom situations. While further research is needed, the results of this study include practices for enhancing teacher awareness of intuition through systemic-phenomenological exercises which proved to be promising, and a taxonomy of effects related to pedagogical tact in the classroom.
\end{abstract}

Keywords Pedagogical tact · Intuition · Teacher professional development program · Systemicphenomenological exercises

Gerbert Sipman

gerbert.sipman@han.nl

Extended author information available on the last page of the article 


\section{Introduction}

In occupations that require handling the complexity of situations in split-seconds (e.g. army commanders, emergency room nurses, firefighters, and air traffic controllers) intuition has shown to be an important quality (Langan-Fox and Vranic 2011). Intuition is often defined as a form of understanding that is rapid and spontaneous, without the need for conscious thought (e.g. Dörfler and Eden 2014), which can facilitate split-second problem solving, decision making, and creativity (Dane and Pratt 2009). Intuition can process information quickly and effortlessly, while reasoning takes time and effort (Sinclair 2011). Moreover, humans can think consciously about only a handful of factors at once, whereas intuition can weigh and integrate many factors in split-seconds (Dijksterhuis 2007). Despite research that shows that intuition can be more accurate than reasoning in complex situations (Pretz 2011), and that deliberation can hinder te quality of judgment and choice (Dijkstra et al. 2012), scholars have also warned about the dangers of relying on intuition (e.g. Winch et al. 2015). This may explain why limited scholarship has been devoted to developing intuitive qualities.

The present study hence aimed to investigate if and how to develop one's intuitive qualities for split-second acting. For this purpose, a systemic-phenomenological approach was chosen. On the one hand, occupations that require split-second handling of complex situations are multifaceted, and therefore require systemic rather than singular or simplistic approaches. Systemic approaches can help to acknowledge real needs of and to find essential solutions in social systems (Thölke 2007). On the other hand, effectively using intuition depends on the extent to which people are able to access and utilize their non-conscious mind (Strick and Dijksterhuis 2011). As people often fail to attend to their intuitions (Hofmann and Wilson 2010), for enhancing one's awareness of intuitions a phenomenological approach can be of use. Intuitions have a phenomenological character (Koksvik 2017), and phenomenologists particularly investigate inner experiences (Maso et al. 2004).

The study was set in the context of primary, secondary and higher education. Teachers face the day-by-day and minute-by-minute challenge of responding appropriately and in splitseconds to the diverse and often complex situations arising in their classrooms (Eaude 2014). Classroom situations are dynamic (learning) systems in which the context plays a determining role (Ell et al. 2017), because educational realities are constructed by different social actors in complex interaction processes (Astaíza-Martínez et al. 2020). Guidelines for dealing with the system dynamics that emerge through these complex interaction processes rarely exist (Bakx 2015), because classroom events are only partially predictable and controllable (Wolff 2015). This is a serious issue, because it is both crucial and challenging to prepare (future) teachers to perform this elusive aspect of their job. Doing so depends on judgment, a capacity which typically requires practice over time (Sinclair 2011) and yet, teachers require this ability from the very start of their careers. The ability of teachers to appropriately handle such complex classroom situations, which has been conceptualized as pedagogical tact, is a key competence for teachers which heavily depends on an intuitive sensibility and sensitivity (van Manen 2015). In fact, given that, for instance, up to $31 \%$ of the Dutch teachers in secondary education abandons education within the first 5 years of their careers (Kennisrotonde 2019), it seems crucial to find ways to support teachers to develop their abilities for acting in the heat of the moment.

Existing literature on enhancing teachers' pedagogical tact focuses primarily on learning about the philosophy of education (Fišer 1972), self-examination to overcome compulsions (Vagle 2011), or reflecting on experiences in practice (van Manen 2015). However, literature 
on improving intuition for teacher pedagogical tact is extremely limited. The present study was undertaken to address this gap. Specifically, this study explored how a systemicphenomenological professional development program (PDP) could increase teachers' intuitive qualities, and inventoried the kinds of effects this could have on teachers' pedagogical tact in the classroom. The following section reviews the systemic-phenomenological literature, on which the PDP was based.

\section{Literature Review}

With the ultimate goal of supporting teachers in developing their pedagogical tact, this section begins by reviewing literature on how a systemic approach and its phenomenological character can enhance intuition. Subsequently, it explains how such exercises can improve the use of two different forms of intuition. Thereafter, it describes five learning processes for developing intuition, and specific practices to trigger them.

\section{Systemic-Phenomenological Exercises}

In the PDP we chose to apply a systemic-phenomenological approach (Roevens 2008), which diverges from other systemic approaches such as structuralist community psychology (Seidman 1988), critical systems thinking (Midgley 1996), or interpretive systemology (Fuenmayor et al. 1991). In general, systemic approaches aim to grasp the complexity of social systems by investigating interaction-patterns (Cohen 2006) that underly, drive and govern them. Social systems need to be interpreted as integrated wholes of which its components interact and conjoin in such a way that they cannot be reduced to smaller units without losing their properties (Capra 1996). In complex systems such as classroom settings non-systemic approaches are less appropriate, because for understanding and/or changing behavior one needs to be able to identify the web of relationships and interconnections within the system (de Rosnay 1997). Systemic approaches aim to make visible the emergence of qualities that cannot be identified from analytical observation (Bertalanffy 1989), emphasize intersubjective understanding and empathy (Bruyn 1966), and require both synthesis through intuition and logical deduction, with the latter being needed to classify and debug the contents of such intuitive apprehensions (Terra and Passador 2015).

Systemic-phenomenological approaches can also be distinguished from other systemic approaches. Based on the existential-phenomenology of scholars such as Brentano, Husserl, Merleau-Ponty and Heidegger, phenomenologists aim to study pre-reflective experiences (van Manen 2011) by focusing on the content of inner experiences (Maso et al. 2004). In Husserl's phenomenology, the gaps in an intentional act of judgement must be filled through intuition and not with sensorial perceptions (Husserl 1982). In this context intuitions should not be seen as the opposite of ratio, but as the opposite of the senses (Terra and Passador 2015). The use of intuition for sensing the essence of a whole therefore plays a key role in phenomenological approaches. As such, systemic-phenomenological approaches focus on the investigation of social systems through the direct experience of sensations, reflections, and intuitions (Thölke et al. 2013).

Systemic-phenomenological exercises can include meditation, but are mostly known as embodied exercises, in which people physically represent elements of social systems by embodying, for instance, persons of a family, organization, etc. These exercises build on the 
premise that an invisible field of information exists in social systems (Horn and Brick 2009). Human nervous systems are able to detect and react to signals from this field, which operates influentially yet subtly just below our conscious level of awareness (McCraty and Zayas 2014). In these exercises, by physically representing system elements, this invisible yet phenomenologically noticeable field of information is created (Thölke and Herder-Wynne 2013). This field can be investigated by sharing intuitive sensations, feelings and reflections that emerge (Thölke et al. 2013). By sharing the emerging intuitive information about the elements that are represented, hidden patterns can be revealed (Jurg 2010). While such exercises have been criticized as purely being role play and not being genuine representations of systems, experts recognize that participants reported great accuracy and new insights that have been provided (DGSF 2003). From the exercises participants gain new viewpoints, a deeper understanding of the complexity of social systems, and often an increased level of respect for that particular system (Emberger 2010). Systemic-phenomenological exercises have been shown to help foster awareness of and sensitivity to issues that arise in classrooms (Ingham and James 2004). The method section (see especially Box 1) describes how embodied exercises were used in the PDP.

\section{Enhancing Two Main Forms of Intuition}

Systemic-phenomenological exercises might support the development of two main forms of intuition, each of which is relevant to this study. On the one hand, systemic approaches (in general) can improve the use of intuitions that build on prior knowledge or experiences, also known as 'local' intuition. This form of intuition can result from automated thinking processes (Pretz 2011) or connection of memory fragments into new information structures (Sinclair 2011). Building on prior experiences, local intuitions may be infused with personal feelings, which, for instance, can lead to confirmation bias (Vanlommel et al. 2018). This kind of intuition can be developed by focusing on conscious inhibition of information processes by screening automatic actions before following them (Hogarth 2001), or recognizing and countering confirmation bias and other sources of error (Sadler-Smith and Burke 2009). Since systemic exercises can offer deeper understanding of social systems (Emberger 2010), they can instigate new perspectives during reflection, for example, on teachers' personal behavior patterns or how social systems (e.g. pupils, classes) work. Reflection on personal behavior patterns can improve automated thinking processes, while increasing knowledge of social systems can also lead to new connections of information structures.

At the same time, systemic-phenomenological approaches can enhance the conscious use of 'gut feelings', referred to in intuition literature as 'nonlocal' intuitions. These intuitions cannot be explained by past knowledge or environmental signals (McCraty and Zayas 2014). They emerge subtly (Sadler-Smith 2010), and therefore require increasing awareness of intuitive signals through, as is recommended mostly, meditative exercises (e.g. Sadler-Smith and Shefy 2007). Alternatively, as mentioned above, embodied exercises can help people become aware of their gut feelings by representing social system elements. By increasing awareness of these intuitions, it can become possible to take these signals into account. Recognizing that gut feelings are not infallible, the goal is merely to extend one's receptive capabilities for sensing what is needed in social systems (Thölke 2007). 


\section{Five Learning Processes for Developing Intuition through Systemic-Phenomenological Approaches}

While through the combination of increasing teachers' understanding of the complexity of social systems and sensitizing awareness of intuitive signals systemicphenomenological exercises seem to be promising for improving participants' awareness of (local and nonlocal) intuitions, their potential depends on how the exercises are enacted. Based on the literature described subsequently, we distinguish five kinds of learning processes that are crucial for heightening awareness of intuitions: being in the moment; sensing intuitive signals; distinguishing between rational, affective and intuitive signals; questioning behavior patterns of self and others; and withholding judgment. First, gut feelings often emerge subtly (Sadler-Smith 2010) and being in the moment sensitizes one's intuitive perception (Claxton et al. 2011). Second, since people often fail to attend to their intuitions (Hofmann and Wilson 2010) it is important to learn to sense those signals. Third, one needs to learn to distinguish between rational, affective and intuitive signals (Sipman et al. 2021). This is because intuitive signals can be overwhelmed by the stronger effects of personal emotions (Sadler-Smith 2010), and intuitions can emerge in the form of thoughts and feelings. Fourth, literature endorses understanding of the situation in which pupil's behavior occurs for improving teachers' pedagogically tactful handling of complex classroom situations (e.g. van Manen 2015), and teachers need to overcome personal compulsions by constantly examining who they are in relation to their pupils within the teaching context (Vagle 2011). This requires questioning behavior patterns in relation to oneself as well as social systems such as pupil(s) and class(es). Fifth, withholding judgment can support teacher handling of complex classroom situations, as nonjudgmental understanding can help teachers to build relationships with their pupils (van Manen 1991). Furthermore, putting further assessment on hold can help mitigate biased intuitive information processing (SadlerSmith and Burke 2009).

\section{Specific Practices to Trigger the Learning Processes}

Literature was also reviewed to identify practices that could engender the aforementioned learning processes. Five practices were identified, and we present them here in the sequence that we believe could be the most productive: check-in, meditative exercise, theory, embodied exercise, and check-out. First, during the check-in, the participants come together as a group and develop their sense of belonging, which is an important pre-requisite for systemicphenomenological exercises (Genee and Konsten 2017). The second activity is what we call shifting to intuition through meditative exercises, which is recommended in the literature for being in the moment (e.g. Anthony 2006; Burke and Sadler-Smith 2011). Frequent practice of shifting to intuition can ease the transition into this state in other contexts (Tomasino 2011). Third, participants require knowledge of the theory behind the systemic approach, since this can offer new viewpoints on and deeper understanding of the behavior of themselves, pupils and classes (Emberger 2010). This can support questioning behavior patterns of self and others, as well as withholding judgment. Fourth, participants represent behavior patterns of self and others in embodied exercises, which can increase awareness for both sensing intuitive signals and distinguishing between rational, affective and intuitive signals; embodied exercises can extend one's receptive capabilities (Thölke 2007). In pairs the participants investigate 
personal cases, through which behavior patterns of self and others are questioned. Emerging new viewpoints on the behavior of both the teachers themselves, and their pupils/classes (Emberger 2010) can support withholding judgment. By questioning personal behavioral patterns and other social systems, the use of local forms of intuition can be improved. Fifth, at the end of the session, participants need to check out from the relatively vulnerable session mode.

\section{Method}

\section{Aim and Approach}

As described above, we reviewed literature on improving intuition to identify potential pathways for enhancing teacher intuitive pedagogical tact. This resulted in a basic understanding of how systemic-phenomenological exercises can support the development of two forms of intuition. Digging deeper, we came to understand that these exercises can bring about five learning processes, and we derived five sequential practices from the literature which seem essential for stimulating those learning processes. This section describes how we explored the application of these insights in a PDP. It begins with the research questions and an overview of the approach, before detailing the PDP intervention and describing the participants, instruments, and data analysis.

The study consisted of two phases, each guided by a separate research question. The first phase was based on the literature review described above, and investigated whether, how and to what extent the systemic-phenomenological exercises, when enacted according to the five sequential practices, yielded the intended learning processes for teacher awareness of (the two forms of) intuition. This was guided by the first research question, "What practices contribute to the envisioned learning processes for enhancing teacher awareness of intuitions?". The second phase speaks directly to the gap in existing literature, as it explored if and how these activities impacted the classroom. This was guided by the second research question, "What types of effects does the PDP yield on teachers' pedagogically tactful handling of complex classroom situations?". For both phases, a qualitative approach was chosen, since this is appropriate for exploring new topics (de Boer and Smaling 2011). Table 1 gives a preview of the methods used, which will be elaborated upon in the sections below.

\section{The PDP Intervention}

Based on the learning processes and practices that are described in the literature review, a PDP was developed. The resulting PDP was implemented over six biweekly sessions of $3 \mathrm{~h}$ each. During the check-in for each session, participants were welcomed and invited to share how they felt 'in the now'. The structure and focus of the session were explained, and rules particularly self-leadership and privacy - were repeated. For the shift toward intuition, participants were offered meditative exercises. Then, in the theoretical segments, the complexity of a systemic perspective on social systems was explained in an interactive lecture, with increasing depth across the sessions. This aligned with the background reading participants had received prior to the start, which explained systemic perspectives on behavior of social systems in the educational context. Systemic principles were related to family systems in session 1, to help understand the behavior of individuals. This kind of understanding is needed for grasping 
similar principles with regard to class or team systems (session 2: groups). This in turn helps for transfer to school systems (session 3: organizations), which helps to understanding pupils' behavioral problems from a systemic point of view (session 4). In session 5, in embodied exercises participants investigated for themselves how to transfer what they had learned into practice, and session 6 was about reflection on personal learning and how the PDP contributed to that (or not). After the theory in each session, the participants investigated cases of the participants themselves related to the theme of the session in embodied exercises (e.g. their family or class system). They worked in pairs, each session with a different 'buddy' (exercise partner). Box 1 provides an example of an embodied exercise. Finally, in the check-out the participants shared experiences and insights, discussed questions, and so forth before looking forward to the next session and saying goodbye.

\section{Participants}

This research was carried out in primary, secondary and higher education in the Netherlands. Two school districts from Arnhem joined the project, as they had been struggling to recruit teachers who are able to deal with the diversity of their urban schools. Two schools for secondary education in Nijmegen and Eindhoven requested to participate, because they were in search for ways to support their teachers in dealing with the complex diversity of their pupil population. Furthermore, two higher education institutes in Arnhem, Nijmegen and Eindhoven invited teachers to engage, since they recognized the potential of enhancing intuition for teachers' pedagogical tact.

Four kinds of teachers participated in this study, namely in-service primary teachers (PI) pre-service primary teachers (PP), in-service secondary teachers (SI), and in-service teachers in higher education (HI). All participants, except the SIs, were partners of the teacher education college in which the first author of this article works. The PIs were invited to participate in the PDP through the principals of their schools, the PPs and HIs could choose the PDP from

Box 1 Anecdote of embodied exercise example from PDP session 4

The PDP participants practice pairwise (A and B) in designated parts of the drama room. B thinks of a pupil who challenges her pedagogical tact and intuitively lays placemats on the floor, opposite to each other to represent the pupil and herself. The placemats indicate the location of each person and the emotional distance between them. Before A and B start to explore the social system, they take some time for being in the moment. Then, B steps on her own placemat and A steps on the placemat of the pupil. Both take the time to sense emerging intuitions and try to distinguish these from other signals. They start sharing the emerging intuitions, by expressing the thoughts, feelings, sensations and tendencies that emerge from the placemat, and what happens when they make contact. A moves her placemat, and is invited to follow the emerging intuitions.

In the second phase, one by one, the nuclear families of B and the pupil are added with additional placemats, as in a systemic-phenomenological approach one's behavior patterns are often related to the behavior patterns that one has developed in the nuclear family. Then both A and B share the changes they perceive because of the added elements of the social system. B stays on her own placemat, whereas A explores B's nuclear family (not the pupil's nuclear family, since this is considered to be unethical).

In the third phase, again one by one, placemats for elements of the pupil's class are added, such as a co-teacher, the pupils in 3-4 groups, etc. A represents these elements for investigating the interaction with the other elements, while B investigates the impact of the (interaction of the) elements on her thoughts, feelings, sensations and tendencies. When necessary, B is encouraged to withhold his/her judgments.

In the fourth phase, the school team is added (in parts) to explore its influences on the other elements of the classroom practice. At the end of the exercise, A and B reflect together by combining their experiences to the theory of the theoretical segment of the session. Thereafter, A and B change roles. 
optional courses within the institute. The SIs were invited through contact persons at their schools, which were acquaintances of the first author. All participants could decide whether to participate in the PDP after reading a short description of the goals, structure and approach to be used in the PDP. Participation was with permission of their executives and outside of the school hours. The groups were deliberately small (5-11 participants), because the embodied exercises require a lot of space and the facilitation is intensive.

Phase 1 participants included: two groups of in-service primary teachers (PI-1A, $n=9$; PI$1 \mathrm{~B}, n=8$ ) and one group of pre-service primary teachers (PP-1, $n=5)$ for a total of 20 women and two men, ranging in age from 20 to 55 years. Five groups participated in phase 2: one group of in-service primary teachers (PI-2; $n=7$ ), one group of pre-service primary teachers (PP-2; $n=10$ ), two groups of in-service secondary teachers (SI-2A, $n=9 ; \mathrm{SI}-2 \mathrm{~B}, n=11$ ) and a group of in-service teachers in higher education (HI- $; n=5)$. In total, 36 women and 6 men, aged 19 to 62 years participated in phase 2 .

Across both phases, each group was led by pairs of facilitators of which there were 7 in total ( 3 women and 4 men, aged 28 to 63). The facilitators were colleagues of the first author of this article, who had invited all of his colleagues who had previously been trained in the use of systemic approaches. The first author trained these colleagues to facilitate the PDP, and the facilitators were purposefully assigned to different groups to mitigate the chance that effects were based on facilitator characteristics.

\section{Data Sources}

In phases 1 and 2, participants wrote reflection logs after PDP sessions 1 through 5 . This approach has been recommended for evaluating the process of professional development programs (Baarda et al. 2013), as reflection logs allow participants to step back from the action and inquire into what is happening in oneself, and in relation to others (Stefanac and Krot 2015). In contrast to other data sources (e.g. interviews or observations), the use of reflection logs enabled us to capture the participant experiences in the PDP sessions (relevant to RQ1) as well as outside of the PDP sessions (relevant to RQ2). Further, because they

Table 1 Methodological preview

Phase 1 (RQ1)

\begin{tabular}{|c|c|}
\hline $\begin{array}{l}\text { Primary } \\
\text { focus }\end{array}$ & $\begin{array}{l}\text { Investigating which practices contributed to the } \\
\text { envisioned learning processes }\end{array}$ \\
\hline Participants & $\begin{array}{l}\text { - PI: Primary education In-service teachers }(n=17) \\
\text { - PP. Primary education Pre-service teachers }(n=5)\end{array}$ \\
\hline
\end{tabular}

\begin{tabular}{|c|c|}
\hline $\begin{array}{l}\text { Data } \\
\quad \text { sources }\end{array}$ & $\begin{array}{l}\text { - Participant reflection logs (during the intervention) } \\
\text { - Participant focus group discussions }\end{array}$ \\
\hline $\begin{array}{l}\text { Data } \\
\quad \text { analysis }\end{array}$ & $\begin{array}{l}\text { Deductive analysis after PDP: } \\
\text { - practices } \\
\text { - learning processes }\end{array}$ \\
\hline
\end{tabular}

Phase 2 (RQ2)

Exploring the PDP effects on teachers' in the classroom

- PI: Primary education In-service teachers $(n=7)$

- PP: Primary education Pre-service teachers $(n=10)$

- SI: Secondary education In-service teachers $(n=20)$

- HI: Higher education In-service teachers $(n=5)$

- Participant reflection logs (during the intervention)

- Participant focus group discussions

Inductive analysis focused on:

- Teacher performance

- Classroom outcomes 
prompted reflection, they supported participants' learning processes. The participants were asked to digitally hand in their reflection logs before the next session, and they were purposely invited to freely share in these logs whatever had struck or touched them to be able to explore the operation and effects of the PDP broadly. To encourage natural, authentic responses and mitigate risk of steering participant reactions, only limited guidelines were given. Specifically related to RQ1, participants were requested to respond to open-ended questions concerning their experiences in the different PDP exercises and their learning moments during the PDP session. Related to RQ2, they were asked to describe any transfer of PDP insights into practice after the session and or any effects on themselves, pupil(s) or class.

Further, after reflecting on their personal learning processes at the end of session 6 , the participants were invited to comment on the structure, meetings, content, facilitators, and other aspects of the PDP in a focus group discussion. This was deemed the most feasible approach to ensure that all voices would be heard (given the heterogeneous groups, $100 \%$ representation seemed prudent). Such focus group discussions are appropriate when no personal interests are at stake, as is the case in this study, but also have the advantage participants can evoke new ideas in each other (Baarda et al. 2013). A research assistant took notes during the discussion and member checking was undertaken by giving a verbal summary of the main feedback points at the end of the session. The participants were invited to correct, supplement, or omit any of the points made.

Further, preparatory to data analysis, facilitators participated in focus group discussions (separate from the PDP participants) after each group's completion of the PDP. These semistructured discussions focused on the PDP practices and learning processes. While these discussions were not used as primary data sources, they did provide contextual clarification which aided data analysis. The discussions were recorded, and summaries of the facilitator group interviews were member-checked to guard their validity and reliability (SantiagoDelefosse et al. 2015).

\section{Data Analysis}

The reflection logs and reports of the participant focus group discussions were first analyzed separately, and later the findings were compared. The analysis of both data sources in both phases was qualitative. However, the specific analysis approach used in phase 1 differed from that used in phase 2 .

To answer the first research question, deductive analysis was undertaken on the data gathered in phase 1 to understand if and how the PDP practices influenced participant learning experiences. In the deductive analysis, i.e. top-down approach that starts from a priori theoretical structures (van Staa and Evers 2010), we first coded for relevance to the five learning processes or practices that could trigger them, as described in the literature review. Next, any relevant connections between the learning and practices were identified. Table 2 shows example quotes from reflection logs for each of the five learning processes; texts in italics constitute connections with PDP practices. This approach was chosen because we wanted to investigate if and how the PDP practices contributed to participant awareness of intuitions.

In phase 2, the goal was to inventory types of PDP effects that transferred to the classroom. Rather than work from a priori assumptions, we opted for inductive analysis, i.e. a bottom-up approach (van Staa and Evers 2010), to answer the second research question. Namely, codes for text fragments were generated based on what was found in the data that were gathered in 
Table 2 Example quotes of deductive analysis from participant reflection logs phase 1 (italicized text denotes connection with PDP practices)

\begin{tabular}{lc}
\hline PDP learning processes & Example quotes \\
\hline Being in the moment & HI-2: The bustle of the morning was still in my head. I could quickly \\
& leave this behind in the meditation. Relaxed but also curious, I \\
entered into the rest of the meeting. & PI-1b: When the facilitator explained the [embodied] exercise I could \\
Sensing intuitive signals & not imagine that I would be able to sense anything at all about my \\
& buddy's family. Extraordinary to experience how a family that I do \\
& not know is related to each other. \\
& SI-2b: In the [embodied] exercise I learned 'to leave what's there's and \\
to take what's mine'; a practical tool that I can use in practice. \\
Pistinguishing between rational, \\
Puffective and intuitive signals \\
class. In the [embodied] exercise I learned that he needs more \\
and others \\
space. I gave it a try, which led to success...the lesson with his class \\
was great. \\
HI-2: In an [embodied] exercise about a student in my class, I met 'the \\
judgment' in my life; the effect was that I became more accessible \\
and softer toward him.
\end{tabular}

phase 2, and iteratively refined as the analysis ensued. Subsequently, individual codes were categorized into themes, and the themes were grouped in overarching types of effects in relation to teachers' awareness and impact. Table 3 shows two main types of effects within awareness and impact, respectively, and gives examples of the themes identified within each.

To establish coding reliability, Atlas.ti (version 7) was used in both phases. Peer debriefing sessions took place regularly to ensure that coding was consistent. These sessions serve as a viable alternative for joint coding or inter-coder reliability checks (Evers 2015).

\section{Results}

This section describes the results of research phases 1 and 2. The results of research phase 1 are structured in accordance with the essential learning processes that were used for the deductive analysis. The themes that emerged in research phase 2 after inductive analysis were categorized in four main groups: awareness of intuitions, individual awareness, classroom performance, and classroom outcomes. The results section is structured accordingly, and in Fig. 1 the (hypothesized) relationships between these main groups are visualized in a taxonomy of PDP effects. The solid arrows indicate relationships that were clearly identified in the results, while the dashed arrows denote hypotheses based on the findings, which warrant further investigation.

\section{$R Q$ 1: What practices contribute to the learning processes for enhancing teachers' awareness of intuitions?}

\section{Being in the Moment}

In the reflection logs, 11 participants $(50 \%)$ referred to being in the moment, which seemed particularly instigated by the meditative exercises. For instance, a participant wrote: 'Taking time to get into contact with yourself, helps me becoming aware of my feelings and to open up 
Table 3 Example quotes of inductive analysis from participant reflection logs phase 2
Types of effects
Example quotes

Awareness Awareness of intuitions

Noticing automated thinking processes

SI-2a: I realized that I was projecting the system of my own nuclear family on a pupil; I now doubt whether I act professionally enough and try to look at this pupil differently.

Connecting (new) memory fragments

PI-2: During lessons I am more aware of the roles pupils have in class and my influence on these processes.

Acknowledging gut feelings SI-2a: In the session I noticed that my intuition is right rather often, that I 'just already know things'; in classroom I now dare to rely on them more.

Individual awareness

Personal well-being

HI-2: We started with a meditation about our ancestors, which made me feel good: firm, connected, positive; I still feel these positive qualities in me.

Professional self

Understanding pupils

PP-2: My mentor said to me that she had noticed that I am more at ease during my lessons. This certainly has to do with the PDP, it becomes more and more clear what place I have to take in class.

SI-2a: In the [embodied] exercise I saw that my pupil's problem behavior is the only way she can react and that it frustrates her when I address this behavior; in classroom, I now have an eye for her side more.

Impact Classroom performance Seeking pupils' needs

PI-1: When my pupils enter the classroom after the weekend, I sense how they are doing. I sat next to a girl and just "knew" that something was wrong.

Appropriate (split-second) pedagogical actions

PP-2: In the [embodied] exercise I realized that the pupil and I have comparable backgrounds, which helped me to establish a more professional distance; I am better able to react to him in a more relaxed and positive way, I remain calmer when his behavior troubles me.

Classroom outcomes

Positive relationships with pupils

PP-1: I have gained insight into my relation with R., at first he was far from me. Now, he searches for contact and even is happy when I am in front of the class.

Balanced interactions

HI-2: When I feel tired, I try to take a moment to rebalance myself and that helps to deal better with my pupils; I am a 'nicer teacher'.

Attending to pupils' autonomy

PI-2: I try to give my pupils a bit more space, without me being in the lead and taking over control constantly.

for others' (PI-1b). For three other participants the meditative exercises were rather challenging, which they described with comments such as: 'I tried to relax and let things be, but it seemed as if I was blocking myself' (PI-1a). Still, other PIs indicated that such exercises 'open up connections with others' (PI-1a), 'support settling in the moment' (PI-1b), or 'help to register my intuitions' (PI-1b); while PP-1s thought the exercises, for instance, 'lead to inner peace and concentration' and 'increase my bodily awareness'.

\section{Sensing Intuitive Signals}

Next, all participants wrote about sensing intuitive signals in the embodied exercises. On the one hand, participants sensed intuitive signals of their buddy, who was, of course, present in the room; for example: 'My buddy tried to sense what is going on in my class. It was extraordinary that she could describe how I feel toward certain pupils' (PI-1a). On the other 


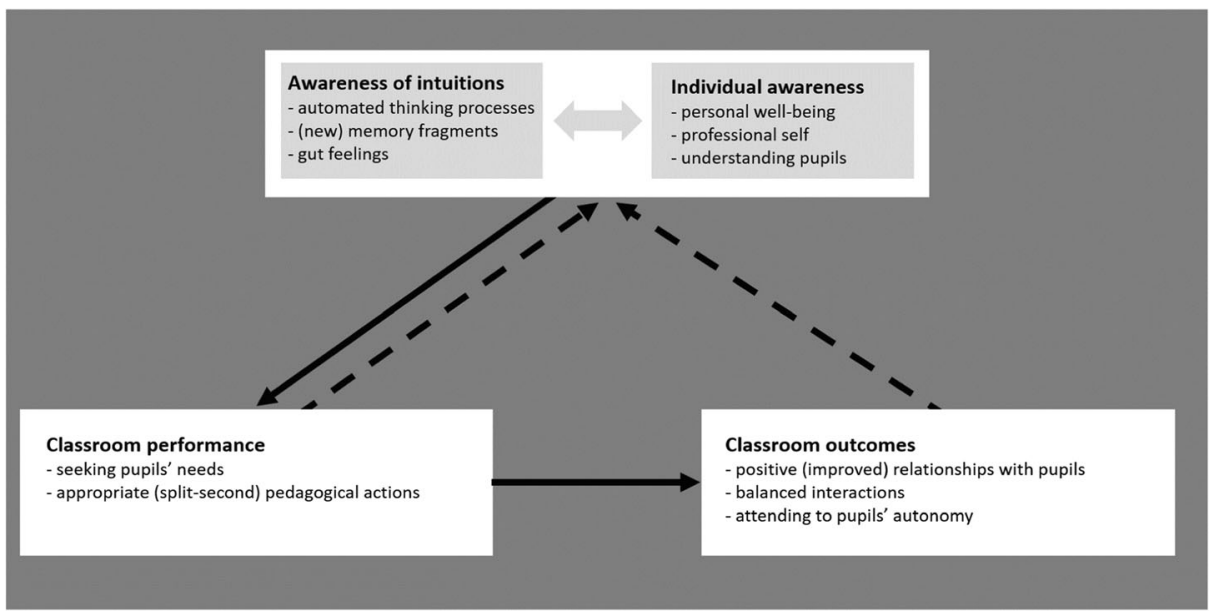

Fig. 1 Taxonomy of effects with identified (solid) and hypothesized (dashed) relationships

hand, the participants sensed intuitive signals of persons of their buddy's social systems who were not present in the room; for example: 'My buddy sensed my mom and expressed literally a sentence which she often uses; I was touched' (PI-1a), or 'I represented my buddy's "problem pupil" and just naturally started moving back and forth; I just knew that he felt uncomfortable in that place' (PI-1b). Most participants seemed to experience a paradigm shift, some small and other larger due to the representing exercises. These were at first described as 'mind blowing' (PI-1a) or 'out of this world' (PI-1b), but this changed in the second half of the PDP into 'amazing' (PI-1a), 'valuable' (PI-1b), or 'beautiful' (PP-1).

\section{Distinguishing Signals}

In the embodied exercises, participants also practiced distinguishing between rational, affective and intuitive signals, which they described with comments such as: 'I learned to distinguish between my own emotions and intuitions about others' (PI-1b), or 'I had no idea how intuitions feel' (PP-1). Representation in embodied exercises seems to particularly contribute to registering and distinguishing gut feelings, for example: 'Emotions, images, words emerged in me' (PI-1b). In the systemic-phenomenological exercises, participants learn to recognize the subtlety of intuitions. For instance, a participant wrote: 'Each session I register more signals in the exercises' (PI-1a). It appeared that distinguishing signals is challenging for some participants. Four participants (18\%) specifically noted difficulties with distinguishing between intuitive and rational signals: 'I struggled to get out of my head and into my body' (PI-1b), while five other participants (23\%) acknowledged that distinguishing between intuitive and affective signals is not easy: 'It remains difficult to distinguish feelings from intuitions' (PP1b).

\section{Questioning Behavior Patterns}

After, as well as during the embodied exercises, the participants questioned behavior patterns of self and others. First, all participants except two (91\%) mentioned questioning of personal behavior patterns in their reflection logs; the PDP exercises led to 'emotions' (PP-1) and 
therefore 'you need to be open for this' (PI-1a). In this context the safety in the group was emphasized in the participant focus group discussions, for example: 'due to the safety in the group, I dared to open up and express my feelings' (PP-2). For instance, three participants referred to the rule of self-leadership: 'Knowing that I am in charge helped me to stay in the PDP' (PI-1a). Further, all sets of cohorts emphasized the importance of two facilitators and a small group: 'You get more attention and that is needed' (PI-1b). Application of the systemic principles that were introduced in the theoretical session segments to personal cases during embodied exercises was noted in this regard by 15 of the 20 participants, for example: 'The exercise provided insight into relations within my nuclear family and made me think a lot about why I do the things that I do the way that I do them' (PI-1a), or 'By relating personal insights from the exercises to my job I was able to establish a professional distance' (PI-1b).

Second, the reflection logs of 18 participants $(82 \%)$ contained references to questioning other social systems than the system of oneself, such as pupils and classes. For instance, a participant shared: 'My buddy represented how my pupil feels, which helped me to understand what he needs' (PI-1b). Here, too, the embodied exercises were mentioned as helping them to understand the behavior and needs of pupils or classes, for example: 'This boy needed some space, so I told his classmates to give him some slack' (PI-1a), or 'I finally understand why this group behaves rebelliously, colleagues of mine have cast them out ' (PI-1b). According to 14 participants the systemic theory offers new perspectives on the complex interaction of systems, which was described with comments such as: 'I now understand that my pupils' behavioral problems can have a function for the systems he lives in' (PI-1a), or 'I now understand this class's behavior in relation to my role as a substitute teacher' (PI-1b). It takes time to fully grasp the complexity of the systemic theory, but 'the theory becomes tangible' (PI-1b) in the embodied exercises.

\section{Withholding Judgment}

None of the participants directly referred to withholding judgment in their reflection logs. However, four participants (18\%) reported (in the same or similar terms): 'I have become milder towards myself and others' (PI-1a). The need for facilitators to model a nonjudgmental attitude was mentioned in all the focus group discussions, for example: 'It helps when facilitators go first in being nonjudgmental' (PI-1b). According to participants a nonjudgmental atmosphere can be created, for instance, when: 'everything is okay' (PI-1a), or 'there are no mistakes' (PI-1b). This helps, as a participant mentioned 'to feel free to explore and to experiment' (PI-1b).

\section{$R Q$ 2: What types of effects does the PDP yield on teachers' handling of complex classroom situations?}

\section{Awareness of Intuitions}

Seven participants (17\%) commented in their reflection that the PDP contributed to noticing automated thinking processes, for example: 'I realized that I have quite some presumptions about pupils' (SI-2b). Three of these participants cited this noticing as being instigated by questioning personal behavior patterns, which they described with comments such as: 'I make 
eye-contact with pupils consciously now, before I did this as a sort of habit' (SI-2b), or 'I try to realize that each behavior hides a story, before I start reacting' (HI-2).

Nine participants (21\%) referred to connecting (new) memory fragments in reflection logs, for example: 'I am more aware of systems; not in actions, more a kind of alertness' (HI-2), or 'I pay more attention to the group dynamics in class' (PP-2). The two of them who commented on causes of their establishing these connections both related this to questioning behavior patterns of self and others. For instance, one of them shared: 'Due to the exercise I started seeing certain students as a person again instead of a problem' (HI-2).

The majority of participants (67\%) referred to acknowledging gut feelings in reflection logs, for example: 'I listen to my intuition more' (PP-2). The data showed that consciously using intuition is complex, as it is not easy to distinguish where intuitions come from. For instance, a participant wrote: 'I do sense something, but I doubt whether intuitions are gut feelings or infused with prejudices' (HI-2). The 28 participants who described this output were often not used to relying on their gut feelings. For instance, a participant noted: 'I have always been a rational person and then you shut off your intuition; I try to be open for it, but it's really hard' (SI-2a). Still, it was possible to get into contact with intuition, for example: 'I learned that it is much easier than expected to put on my antennas; I know much more than I'm aware of' (SI$2 \mathrm{~b}$ ), or 'I dare to respond to what I sense in groups; I express what I sense and check if I'm right' (HI-2). Of the 28, 11 participants suggested that this output was evoked by representing behavior patterns of self and others in embodied exercises, which they described with comments such as: 'In the exercises, I experienced how it feels to trust my intuitions' (SI$2 \mathrm{a}$ ), or 'By experiencing intuitions in exercises, it becomes easier to work with intuition in practice' (SI-2b). By contrast, five of the 28 participants mentioned that they were able to do this as a result of becoming sensitized to distinguishing signals, for example: 'When I feel something unpleasant, I'm better able to distinguish what belongs to me or to others' (SI-2b), or 'By being aware of what I felt, taking this seriously instead of ignoring it, I was able to confront him' (HI-2).

\section{Individual Awareness}

In the reflection logs, about half of the participants (48\%) claimed that the PDP influenced their personal well-being. For instance, participants mentioned 'At times I still feel insecure, but I'm less upset and get myself back on my feet quicker' (PI-2), or 'I am more "me" now' (PP-2). Eight of these 20 participants referred to questioning personal behavior patterns as instigating this output, for example: 'I became aware of the role I have in my family, which helped me to understand my behavior; I feel richer, more complete' (SI-2a), 'I now understand why others drain me out and started taking better care of myself' (PI-2), or 'I was able to let go of my mom's grief; I feel liberated and that I can stand up for myself' (SI-2a). The PDP was described with words such as 'emotional' (SI-2b) and 'confronting' (HI-2).

Further, $79 \%$ of participants reported positive effects on their professional self (in various forms), such as: 'I am more secure and relaxed in working with the pupils' (PP-2), 'I am better able to set boundaries' (SI-2a), 'I'm not going to be a copy of my colleague anymore' (PI-2), 'I now feel more supported by my mentor' (PP-2), or 'I realized that my influence as a teacher is limited, somehow this brings peace' (HI-2). Of the 33 participants who mentioned this output, 17 suggested that questioning personal behavior patterns contributed to this, while 11 referred to the role played by questioning other social systems; for example: 'I can react from my nuclear system or my professional system; when I react from the latter I can park personal stuff 
and react to behavior of pupils without annoying myself' (SI-2a), 'I am aware that my pupils sense the lack of balance in our team, which I can't solve; I try to focus on what I can do' (SI2a), or 'I now understand what went wrong between me and the class I took over' (SI-2a). For three participants, being in the moment improved their professional self, which they described with comments such as: 'Prior to difficult lessons or meetings I take time to shift to stay close to myself' (PI-2), or 'Somehow I can stay out of my irritation better when I work more intuitively in class' (PI-2).

For 13 participants (31\%), the combination of representing and questioning of behavior patterns of self and others in the embodied exercises yielded positive effects on understanding the perspectives of individual pupils. For instance, participants shared: 'The systemic approach offers me new perspectives on my pupils' behavior, which helps me to attune to their needs' (PI-2), or 'In the PDP exercise I learned that I should not be so much on top of her, she needs me to think along with her' (SI-2b). These new perspectives seemed to support participants to attend to their pupils' needs in classroom. For instance, participants shared: 'Due to the PDP session I know why he behaves the way he behaves, I now am better able to help him' (PP-2), or 'My view of this pupil has changed, in the classroom I empathize with her more' (SI-2b).

\section{Classroom Performance}

Six participants (14\%) mentioned using intuition consciously in practice for seeking pupils' needs. For instance, participants mentioned: 'I intuitively scanned the pupil and sensed a sore throat, which he confirmed' (PI-2), or 'I sensed what he needed and felt very clearly that I could not help this boy, I referred him to specialized aid' (HI-2). Five of the 19 participants said they could do so because they were attuned to the moment by shifting to intuition, for example: 'By scanning my body before lessons, I was able to sense better and quicker what he needed of me' (PP-2).

Furthermore, the clear majority of participants $(86 \%)$ wrote in their reflection logs about appropriate (split-second) pedagogical actions in many forms such as: 'I now succeed in remaining friendly although he defies me' (PP-2), 'I try to pay attention to all pupils, especially to those I tend to forget' (SI-2a), 'For the sense of safety of other pupils I excluded this boy' (SI-2b), or 'I express my expectations more clearly' (HI-2). Thirteen of these 36 participants explicitly related actions to intuition, for example: 'I had unexplainable gut feelings about this girl; when I asked her, it appeared that her granny is very sick' (PP-2), 'I intuitively gave a difficult pupil my chair in front of the class instead of isolating him' (SI-2b), or 'I expressed my intuitions and all of a sudden she opened up' (SI-2b). Two others said in similar words that the PDP helped them realize "that my pupils can "absorb" my negative emotions and I don't want that; I started using positive approaches even more' (PP-2). Seven participants also mentioned other actions related to PDP exercises such as: 'When my pupils are restless, I do some breathing exercises with them to calm them down' (PP-2), 'I use the meditations from the PDP in my class; the pupils even ask for it, they like it' (SI-2a), or 'I used embodied exercises in my lessons, which led to beautiful conversations about education' (HI-2).

\section{Classroom Outcomes}

Twelve participants (29\%) wrote about positive (improved) relationships with pupils in their reflection logs, for example: 'I feel more connected with pupils' (PI-2), 'Our relationship is restored, he now laughs and makes jokes' (SI-2a), or 'I feel better able to tune in to my 
students' (HI-2). One participant related the improved relationship to using intuition in practice: 'Contact with my pupils has changed, as I try to rely on my intuition more' (SI2b), and another participant mentioned that 'By approaching a girl without judging, an open and honest conversation emerged' (SI-2b). Also, four participants reported having paid more attention to their relationships with pupils due to the PDP. For instance, one of them shared: 'I gave a problem pupil some extra attention and now we trust each other more' (PP-2).

Ten participants (24\%) referred to balanced interactions, particularly in the second half of the PDP. Some mentioned that their classroom runs more smoothly due to the PDP, for example: 'I am more clear, which helps the pupils to know what I expect of them' (SI-2a). Others noticed less problem behavior in their classes. For instance, participants shared: 'I asked an angry boy how he felt and he started crying; thereafter he behaved excellently' (PI-2), or 'I let him know more that he belongs to the group and his negative behavior seems to diminish' (SI-2a).

Seven participants $(17 \%)$ referred to attending to pupils' autonomy. For instance, a participant wrote in his reflection log: 'I more often take a step back so that the group can do the work itself instead of taking the lead' (HI-2). Two of these respondents related this to understanding individual pupils, for example: 'I sensed that she needed some strictness, but also some space' (SI-2b). The others related this to increased pupils' autonomy in their groups, which they described with comments such as: 'I try to let the pupils solve problems themselves instead of jumping in immediately' (PI-2).

\section{Conclusions}

This section briefly recaps the key findings and answers the research questions. This study explored how to foster teacher pedagogical tact by improving awareness of intuitions through a systemic-phenomenological approach. The first research question examined if and how PDP practices provided crucial learning processes for improving teacher awareness of intuitions. The findings suggest that meditative exercises support being in the moment, which is needed for engaging in embodied exercises. The embodied exercises support questioning behavior patterns of oneself as well as others within other social systems (pupils, classes); the systemic theoretical input helps the questioning part. The phenomenological component of the embodied exercises also supports learning to sense intuitive signals as well as distinguish between rational, emotional and intuitive signals for attending to what emerges. It seemed that the PDP approach, and particularly the embodied exercises, instigate a paradigm shift. Further, for learning about their own personal behavior patterns, participants need to be open to emotional processes. The PDP approach hence requires a safe learning environment.

The second research question explored the PDP effects. Data revealed effects on teacher awareness of intuitions in classroom and their pedagogically tactful handling of complex classroom situations. First, the PDP helped participants to improve their awareness of intuitions resulting from automated thinking processes or from connecting memory fragments (local intuitions), but the PDP especially helped them improve awareness of gut feelings (nonlocal intuitions) by representing behavior patterns in the embodied exercises. Second, the PDP seems to positively influence teachers' individual awareness. The participants perceive positive effects on their personal well-being, and even more positive effects on their professional self. Besides, understanding pupils' perspective seems to support attending to their needs. In relation to teachers' pedagogically tactful handling of complex classroom situations, 
participants described two types of classroom actions that were supported by the use of intuition: sensing pupils' needs, and taking appropriate (split-second) pedagogical actions. Participants perceived the impact these classroom actions have in terms of better relationships with pupils, classrooms running more smoothly, or even less problem behavior. Several teachers report having increased pupils' autonomy. We therefore, with caution, conclude that the PDP indeed improves not only teacher awareness of intuitions, but teacher individual awareness as well, which ultimately enhances teacher pedagogical tact.

\section{Discussion}

In this section, the results are discussed in light of existing literature. First, attention is given to how the findings related to RQ1, focusing on the PDP and participant experiences in enhancing their intuitive awareness. Then, related to RQ2, attention is given to enhanced intuitive awareness in the classroom and how that impacts pedagogical tact.

\section{Reflections on Findings Related to RQ1}

The results of our study suggest that practices undertaken within the PDP contributed to participant learning, and give indications as to how. First, the findings showed that the systemic perspective instigated reflection on personal behavior patterns. The vast majority of participants reported that the systemic theory, combined with embodied exercises, fostered questioning of behavior patterns of themselves. This is in line with literature suggesting that such an approach radically shifts in perception from conventional views of human behavior (Ingham et al. 2015), and that reflection can help teachers to become aware of their behavior and its sources (Korthagen 2017). Additionally, the new (systemic) perspective on the behavior of social systems appeared to instigate a nonjudgmental attitude not only to towards the participants themselves, but also to their pupils. In line with existing literature (Emberger 2010), they experienced a deeper understanding of and increased respect towards social systems, which seemed to positively influence their individual awareness.

Second, the data revealed how use of local intuition can be improved by increasing knowledge through systemic theory on the behavior and needs of social systems, for establishing (new) connections between existing memories. For example, most participants reported that the systemic theory, particularly when combined with embodied exercises, offered new perspectives on their pupils' behavior, which helped them to better understand their needs. This is in line with literature that suggests that a systemic approach can help to understand the needs of people and/or groups (Thölke 2007), and to develop teachers' sensitivity to issues manifesting in classrooms (Ingham and James 2004).

Third, the paradigm shift that the participants experienced during the PDP suggests that this approach was transformative for them. This shift seems to have been particularly instigated by the phenomenological aspect of the systemic approach. That is, data from the meditative exercises showed that they supported being in the moment and prepared the participants for the embodied exercises. In the embodied exercises, the participants especially reported sensing intuitive signals and distinguishing these intuitions from rational and affective signals. It appeared that becoming aware of intuitive signals was new for many participants, which confirms that people often fail to attend to their intuitions (Hofmann and Wilson 2010). 
Further, in line with literature (e.g. Sinclair 2010), the participants reported that it can be difficult to separate intuitions from rational and affective signals.

\section{Reflections on Findings Related to RQ2}

The results of this study support the assumption that improving awareness of intuitions fosters teachers' pedagogical tact. Further, the taxonomy of effects (Fig. 1) suggests how this takes place. Here, the findings related to RQ2 are discussed in light of the taxonomy elements (respectively awareness of intuitions, individual awareness, classroom performance, and classroom outcomes).

In this study, the participants reported to have particularly become more aware of their gut feelings, which appeared to be supportive for their classroom performance. This is in line with research which has demonstrated that improving awareness of teacher intuition can improve teacher abilities to sense pupils' needs and what happens in classes (Kennedy 2002), and lead to more effective communication, smooth social interactions, and positive relations (McCraty and Zayas 2014). At the same time, people tend to neglect these intuitions (Dijksterhuis and Aarts 2010), and therefore it is important that teachers learn to acknowledge nonlocal intuitions. While both reflection and increasing knowledge of pupils' behavior and needs are often part of teacher education, it is less common to focus on awareness of nonlocal intuition (Anthony 2006).

Our results also indicated that many participants perceived positive effects on their personal well-being, and even more on their professional self. Both aspects of teachers' individual awareness appeared to support their classroom performance, which is in line with previous scholarship that has shown that developing cognitive, emotional, interpersonal, and intrapersonal capacities enables persons to manage the complexities of work (Drago-Severson 2009). When it comes to teachers, self-awareness is said to be a quality of socially and emotionally competent teachers, and their sense of well-being can positively influence the prosocial atmosphere of classrooms (Jennings and Greenberg 2009). In fact, a teachers' professional identity is related to many factors, including their sense of self-efficacy. Research has shown that teachers with high self-efficacy often have better classroom management, are more flexible in instructional methods, are less critical of pupils when they make mistakes, and have greater commitment and enthusiasm for teaching (Steele 2010). Furthermore, The finding of this study also showed positive effects on teachers' understanding of pupils' perspective. Teachers in this study appreciated the examination of themselves in relation to their pupils, as well as how these relations are embedded in the schools and communities in which they teach. This is consistent with recommendations from literature (e.g. Vagle 2011), for becoming more attuned to others and, in so doing, enabling tactful action.

Then, the PDP participants reported effects on their classroom performance, such as seeking pupils' needs and appropriate (split-second) pedagogical actions. These findings are in line with existing literature, which suggests that pedagogically tactful actions emerge when teachers are not hindered by their ego with its prejudices, cynicisms or fears (Bors and Stevens 2013). Further, the participants reported that the systemic theory about the behavior and needs of social systems helped them in seeking their pupils' needs. This is consistent with previous claims that teachers bring into their classes knowledge from multiple domains such as pedagogical content knowledge and curricular knowledge (Fagan 2010). Pedagogically tactful teachers have an eye for, among others, the biographies, backgrounds, and specific circumstances of their pupils (van Manen 1991). Research shows that teachers who really understand their pupils' perspectives are able to attune to their needs (Buyse et al. 2009); and this kind of empathy enhances pupils' learning (Meyers et al. 2019). 
Finally, the participants perceived positive classroom outcomes in relation to two of the three basic psychological needs for self-determination that Ryan and Deci (2002) describe: relationship, and pupil autonomy. The PDP participants noticed positive or even improved relationships with their pupils and (more) balanced interactions, meaning that teachers and their pupils are (mostly) attuned to each other. This is in line with literature that suggests that this attunement helps teachers and pupils to understand each other (Diemel 2019) and that teacher pedagogical tact is a relational phenomenon (Friesen and Osguthorpe 2018). This is important because such balanced interactions can contribute to the prevention of problem behavior in class (Goei and Kleijnen 2009). Furthermore, participants tended to grant their pupils more autonomy, which is also in line with literature on pedagogical tact (Bors and Stevens 2013) as well as self-determination theory (Ryan and Deci 2002). Relating the classroom outcomes to the basic psychological needs for self-determination helped us realize that the third basic psychological need, pupils' sense of competence, was not mentioned by the participants.

\section{Limitations and Future Research}

The results of this study should be considered in light of its limitations. Further, first, we examine the approach of the study from a trustworthiness perspective (Lincoln and Guba 1985). With regard to transferability, it should be noted that this was an initial, small-scale, qualitative exploration with all volunteer participants. Generalization to other contexts hence is limited. However, through the purposive sampling and thick descriptions used, readers may identify implications for their own contexts. In terms of credibility, an alternative to the open-ended approach of this study might be suitable. Namely, asking the participants to reflect on what particularly struck them helped identify highly salient issues, but not practices of the PDP experience which might have been useful but not 'striking'. For instance, embodied exercises may well have influenced withholding judgment, but the data collection approach may not have been sensitive enough to pick this up. More narrowly focused data collection (e.g. asking interviewees to reflect on specific practices) might address this issue, though it would be important not to introduce bias in doing so. While debriefing was undertaken, confirmability could be enhanced in future research. For example, an experimental design in which a control group is not exposed to certain practices of the PDP (e.g. background reading) could help refine understanding of the role played by specific PDP practices. Alternatively, for researching participants' intuitive experiences more thoroughly, phenomenological methods may be useful. For instance, for researching the microdynamics of intuition Petitmengin (2014) recommends elicitation interviews, which help with becoming aware of usually unnoticed parts of (cognitive) processes and describing these with precision. When this process is supported by actual classroom video, multiple interpretations can be shared, which has been previously been deemed useful for raising teacher awareness to specific practices. Finally, future research could increase dependability by triangulating self-report data with perspectives of the facilitators, colleagues or external observers. For investigating phenomena such as intuition and pedagogical tact, interpretive systemology might be of use, as this research approach aims to show the richness of phenomena by exploring the limits of different perspectives on it (Midgley and Ochoa-Arias 2001). For further details on this approach and its origins, please refer to the special issue of this journal dedicated to interpretive systemology (Volume 4, Number 5, 1991). Future research could also be enriched by making use of existing instruments such as the Climate Scale (Donkers et al. 2009) or the International Comparative Analysis of Learning and Teaching (ICALT; Maulana et al. 2015). 
Second, now that an initial taxonomy of effects has been identified, more rigorous methods could be employed to investigate effects. For example, a longer-term experimental design with classroom observations of teacher pedagogical tact and measures for pupil outcomes seems fitting. In this context, we endorse methodological pluralism to enhance the flexibility and effectiveness of practice (Midgley and Ochoa-Arias 2001). Additionally, cluster analysis could be undertaken to validate the taxonomy of effects presented here. Further, while this study considered participant self-reported data to be valuable for generating the initial taxonomy of effects, insight into teachers' classroom practice seems crucial for the effects of the PDP. Figure 1 offers a starting point for further investigation of PDP effects, by portraying the types of effects found and interactions identified in this six-week study (solid lines), as well as relationships that seem highly plausible (dotted lines) based on exiting insights regarding teacher reflection and professional growth over time (e.g. McKenney 2017).

\section{Closing Remarks}

The results of this study suggest that improving awareness of intuitions for teachers' pedagogically tactful handling of complex classroom situations through a systemicphenomenological approach has promising effects on teachers and their experiences in their classrooms. While further empirical research is needed, this study provides a preliminary empirically generated map of how PDP practices contribute to essential learning processes, and practical recommendations about how to improve awareness of intuitions through systemic-phenomenological approaches. The results of this study might also be applicable in other occupations that require tactful improvisations based on more than overt input. Social sector occupations that also focus on the development of people may benefit from attending to their intuitive tact. Sole reliance on intuition seems highly risky, but the results of this study suggest that not attending to intuition may also bring risks. Therefore, we consider it crucial to search for ways to improve awareness of intuition and integration of intuitive signals into handling of classroom challenges.

\section{Declarations Not applicable.}

Open Access This article is licensed under a Creative Commons Attribution 4.0 International License, which permits use, sharing, adaptation, distribution and reproduction in any medium or format, as long as you give appropriate credit to the original author(s) and the source, provide a link to the Creative Commons licence, and indicate if changes were made. The images or other third party material in this article are included in the article's Creative Commons licence, unless indicated otherwise in a credit line to the material. If material is not included in the article's Creative Commons licence and your intended use is not permitted by statutory regulation or exceeds the permitted use, you will need to obtain permission directly from the copyright holder. To view a copy of this licence, visit http://creativecommons.org/licenses/by/4.0/.

\section{References}

Anthony M (2006) Representations of integrated intelligence within classical and contemporary depictions of intelligence and their educational implications. Dissertation, The University of the Sunshine Coast

Astaíza-Martínez A, Mazorco-Salas J, Castillo-Bohórquez M (2020) Teacher-researcher training in higher education: a systems thinking approach. Syst Pract Action Res. https://doi.org/10.1007/s11213-020-09532-x 
Baarda B, Bakker E, Fischer T, Julsing M, Peters V, Velden T, de Goede M (2013) Basisboek kwalitatief onderzoek: Handleiding voor het opzetten en uitvoeren van kwalitatief onderzoek [basics of qualitative research: manual for designing and conducting qualitative research], 3rd edn. Noordhoff, Groningen

Bakx A (2015) De pedagogisch sensitieve leraar: Werken aan brede opbrengsten [the pedagogically sensitive teacher: working on broad yields]. Coutinho, Bussum

Bertalanffy L (1989) A general systems theory. Fondo de Cultura Económica, Mexico

Bors G, Stevens L (2013) Pedagogische tact: Op het goede moment het juiste doen, óók in de ogen van de leerling [pedagogical tact: doing the right thing at the right time, even in the eyes of the pupil]. Garant, Antwerpen-Apeldoorn

Bruyn S (1966) The human perspective in sociology: the methodology of participant observation. Prentice-Hall, Upper Saddle River

Burke L, Sadler-Smith E (2011) Integrating intuition into higher education: a perspective from business management. In: Sinclair M (ed) Handbook of intuition research. Edward Elgar, Cheltenham, pp 237-246

Buyse E, Snoeck G, Bertrands E, Declecq B, Laevers F (2009) Fundamenteel diepte-onderzoek naar krachtige GOK-leeromgevingen: Onderzoeksluik 'betrokkenheid \& welbevinden' [Fundamental in-depth research on powerful GOK learning environments: Research section 'involvement \& well-being']. Steunpunt GOK/ Expertisecentrum Ervaringsgericht Onderwijs, Leuven

Capra F (1996) The web of life: a new scientific understanding of living systems. Anchor Books, New York

Claxton G, Chambers M, Powell G, Lucas B (2011) The learning powered school: pioneering $21^{\text {st }}$ century education. TLO Limited, Bristol

Cohen D (2006) "Family constellations": an innovative systemic phenomenological group process from Germany. Fam J: Couns Ther Couples Fam 14:226-233

Dane E, Pratt M (2009) Conceptualizing and measuring intuition: a review of recent trends. In: Hodgkinson G, Ford J (eds) International review of industrial and organizational psychology. Wiley, Chichester, pp 1-40

de Boer F, Smaling A (2011) Benaderingen in kwalitatief onderzoek: Een inleiding [approaches in qualitative research: an introduction]. Boom Lemma, The Hague

de Rosnay J (1997) Analytic vs. Systemic Approaches. http://pespmcl.vub.ac.be/ANALSYST.html. Accessed 1 Nov 2019

DGSF (2003) Stellungnahme der DGSF zum Thema Familienaufstellungen [DGSF statement on family constellations]. https://www.dgsf.org/themen/berufspolitik/hellinger.htm. Accessed 23 Mar 2020

Diemel K (2019) Kwintessens in het handelen van leraren: Een onderzoek naar pedagogische sensitiviteit in het onderwijs [Quintessence of teaching practices: A study on pedagogical sensitivity in education]. Dissertation, The University of Humanistics Utrecht

Dijksterhuis A (2007) Het slimme onbewuste: Denken met gevoel [the smart unconscious: thinking with affect]. Bert Bakker, Amsterdam

Dijksterhuis A, Aarts H (2010) Goals, attention, and (un)consciousness. Ann Rev Psychol 61:467-490

Dijkstra K, van der Pligt J, van Kleef G, Kerstholt J (2012) Deliberation versus intuition: global versus local processing in judgment and choice. J Exp Soc Psychol 48:1156-1161

Donkers A, Jeninga J, Vermulst A (2009) Klimaatschaal [Climate scale]. Fontys OSO, Tilburg

Dörfler V, Eden C (2014) Research on intuition using intuition. In: Sinclair M (ed) Handbook of intuition research. Edward Elgar, Cheltenham, pp 264-276

Drago-Severson E (2009) Leading adult learning: supporting adult development in our schools. Corwin Press, Thousand Oaks

Eaude M (2014) What makes primary classroom teachers special? Exploring the features of expertise in the primary classroom. Teach Teach Theory Pract 20(1):4-18

Ell F, Haigh M, Cochran-Smith M, Grudnoff L, Ludlow L, Hill M (2017) Mapping a complex system: what influences teacher learning during initial teacher education? Asia-Pac J Teach Educ 45:327-345

Emberger S (2010) How can ECL practice help to establish a positive relationship between schools and parents. Unpublished dissertation, University of Roehampton

Evers J (2015) Kwalitatieve analyse: Kunst én kunde [qualitative analysis: art and skill]. Boom Lemma, Amsterdam

Fagan D (2010) Teacher knowledge as context. Stud Appl Linguist TESOL 10:42-45

Fišer J (1972) The quality of the teacher-pupil relationship: an essay on pedagogical tact. Int Rev Educ 18:467-472

Friesen N, Osguthorpe R (2018) Tact and the pedagogical triangle: the authenticity of teachers in relation. Teach Teach Educ 70:255-264

Fuenmayor R, Bonucci M, Lopez-Garay H (1991) An interpretive-systemic study of the University of Los Andes. Syst Pract 4:507-525

Genee L, Konsten H (2017) Systemisch trainen: Trainen van binnenuit in het geheel [systemic training: training from inside out within the whole]. De Verbinding, Westervoort

Goei S, Kleijnen R (2009) Literatuurstudie Onderwijsraad “Omgang met zorgleerlingen met gedragsproblemen": Eindrapportage [Literature study Dutch Board of Education "Dealing with pupils with behavioral problems": Final report]. https://www.researchgate.net/publication/274371412. Accessed 12 May 2019 
Hofmann W, Wilson T (2010) Consciousness, introspection, and the adaptive unconscious. In: Gawronski B, Payne B (eds) Handbook of implicit social cognition: measurement, theory and applications. Guilford Press, New York, pp 1-16

Hogarth R (2001) Educating intuition. University of Chicago Press, Chicago

Horn K, Brick R (2009) Invisible dynamics. Carl Auer Verlag, Heidelberg

Husserl E (1982) Cartesian meditations: an introduction to phenomenology (D. Cairns, trans). Martinus Nijhoff Publishers, The Hague

Ingham T, James J (2004) Enhancing children's learning: A pilot study of the application of systemic approaches in primary schools. http://www.cwt.roundtablelive.org/resources/Documents/Enhancing\%20Children\% 20Learning2004.pdf. Accessed 28 Aug 2019

Ingham T, Hemming J, James J (2015) Enhancing Children's learning. Self Soc: Internat J Humanist Psychol 33: 41-46

Jennings P, Greenberg M (2009) The prosocial classroom: teacher social and emotional competence in relation to student and classroom outcomes. Rev Educ Res 79:491-525

Jurg W (2010) The perceived usefulness of branding constellations: unraveling branding systems (doctoral dissertation). Het Noorderlicht, Groningen

Kennedy J (2002) Developing intuition in marginal trainees on teaching practice. Eng Lang Teach Educ Dev 7:44-53

Kennisrotonde (2019) Om welke redenen stoppen leraren voortgezet onderwijs binnen vijf jaar? https://www. kennisrotonde.nl/vraag-en-antwoord/uitval-beginnende-docenten-vo\#: :text=Hoeveel\%20startende\% 20leraren\%20precies\%20uitvallen,31\%20procent\%20na\%20vijf\%20jaar. Accessed 17 Jan 2021

Koksvik O (2017) The phenomenology of intuition. Philos Compass 12:1-11

Korthagen F (2017) Inconvenient truths about teacher learning: towards professional development 3.0. Teach Teach 23:387-405

Langan-Fox J, Vranic V (2011) Life, death and intuition in critical occupations. In: Sinclair M (ed) Handbook of intuition research. Edward Elgar, Cheltenham, pp 111-121

Lincoln Y, Guba E (1985) Naturalistic inquiry. Sage Publications, Newbury Park

Maso I, Andringa G, Heusèrr S (2004) De rijkdom van ervaringen: Theorie en praktijk van empirisch fenomenologisch onderzoek [the wealth of experience: theory and practice of empirical phenomenological research]. Lemma BV, Utrecht

Maulana R, Helms-Lorenz M, van de Grift W (2015) Development and evaluation of a questionnaire measuring pre-service teachers teaching behaviour: a Rasch modelling approach. Sch Eff Sch Improv 26:169-194

McCraty R, Zayas M (2014) Intuitive intelligence, self-regulation, and lifting consciousness. Glob Adv Health Med 3:56-65

McKenney S (2017) Een infrastructuur voor de professionele groei van docenten [an infrastructure for the professional growth of teachers]. Inaugural lecture, University of Twente

Meyers S, Rowell K, Wells M, Smith B (2019) Teacher empathy: a model of empathy for teaching for student success. Coll Teach 67:160-168

Midgley G (1996) What is this thing called CST? In: Flood R, Room A (eds) Critical systems thinking: current research and practice. Plenum Press, New York

Midgley G, Ochoa-Arias A (2001) Unfolding a theory of systemic intervention. Syst Pract Action Res 14:615649

Petitmengin C (2014) Researching the microdynamics of intuitive experience. In: Sinclair M (ed) Handbook of research methods on intuition. Edward Elgar, Cheltenham, pp 188-198

Pretz J (2011) Types of intuition: inferential and holistic. In: Sinclair M (ed) Handbook of intuition research. Edward Elgar, Cheltenham, pp 17-27

Roevens J (2008) Systemic constellations work in organizations. ScienceGuide, Amsterdam

Ryan R, Deci E (2002) Overview of self-determination theory: an organismic dialectical perspective. In: Deci E, Ryan R (eds) Handbook of self-determination research. University of Rochester Press, Rochester, pp 3-33

Sadler-Smith E (2010) The intuitive mind. Wiley, Chichester

Sadler-Smith E, Burke L (2009) Fostering intuition in management education: activities and resources. J Manag Educ 33:239-250

Sadler-Smith E, Shefy E (2007) Developing intuitive awareness in management education. Acad Manag Learn Educ 6:186-205

Santiago-Delefosse M, Gavin A, Bruchez C, Stephen S (2015) Diversity of the quality criteria in qualitative research in the health sciences: lessons from a lexicometric analysis composed of 133 guidelines. Forum: Qual Soc Res 16:11

Seidman E (1988) Back to the future, community psychology: unfolding a theory of social intervention. Am J Commun Psychol 16:3-24

Sinclair M (2010) Misconceptions about intuition. Psychol Inq 21:1-9 
Sinclair M (2011) An integrated framework of intuition. In: Sinclair M (ed) Handbook of intuition research. Edward Elgar, Cheltenham, pp 3-16

Sipman G, Martens R, Thölke J, McKenney S (2021) Exploring teacher awareness of intuitions and how it affects classroom practices: conceptual and pragmatic dimensions. Prof Dev Educ https://doi.org/10.1080/ 19415257.2021.1902839

Steele N (2010) Three characteristics of effective teachers. Natl Assoc Music Educ 28:71-78

Stefanac L, Krot M (2015) Using T-groups to develop action research skills in volatile, uncertain, complex, and ambiguous environments. In: Bradbury H (ed) The SAGE handbook of action research (3rd ed). SAGE Reference, Los Angeles, pp 109-117

Strick M, Dijksterhuis A (2011) Intuition and unconscious thought. In: Sinclair M (ed) Handbook of intuition research. Edward Elgar, Cheltenham, pp 28-36

Terra L, Passador J (2015) A phenomenological approach to the study of social systems. Syst Pract Action Res 28:613-627

Thölke J (2007) Leren niet te weten: Een zoektocht rond zinvolle vernieuwing in (onderwijs)organisaties [learning not to know: a search for meaningful renewal of (educational) organizations]. Hogeschool van Arnhem en Nijmegen, Nijmegen

Thölke J, Herder-Wynne F (2013) Innovation from inside out: a brief research report September 2013. Hogeschool van Arnhem en Nijmegen, Nijmegen

Thölke J, Sipman G, Andriessen D, Herder-Wynne F (2013) Making the invisible visible at a teacher education college using awareness-based action research. Proceedings of the 2013 RWL8 conference. Stirling University. http://www.eclfoundation.org/wp-content/uploads/2014/02/Making-the-Invisible-visible-usingawareness-based-action-research.pdf. Accessed 14 May 2017

Tomasino D (2011) The heart in intuition: tools for cultivating intuitive intelligence. In: Sinclair M (ed) Handbook of intuition research. Edward Elgar, Cheltenham, pp 247-260

Vagle M (2011) Critically-oriented pedagogical tact: learning about and through our compulsions as teacher educators. Teach Educ 22:413-426

van Manen M (1991) The tact of teaching. The Althouse Press, Ontario

van Manen M (2011) Fenomenologie: Een kwalitatieve benadering met een verscheidenheid aan tradities [phenomenology: a qualitative approach with a diversity of traditions]. In: de Boer F, Smaling A (eds) Benaderingen in kwalitatief onderzoek: Een inleiding [approaches in qualitative research: an introduction]. Boom Lemma, The Hague, pp 47-56

van Manen M (2015) Pedagogical tact: knowing what to do when you don't know what to do. Routledge, New York

van Staa A, Evers J (2010) 'Thick analysis': Strategie om de kwaliteit van kwalitatieve data-analyse te verhogen ['thick analysis': strategy to increase the quality of qualitative data analysis]. Kwalon 15:5-12

Vanlommel K, van Gasse R, Vanhoof J, van Petegem P (2018) Teachers' high-stakes decision making: how teaching approaches affect rational and intuitive data collection. Teach Teach Educ 71:108-119

Winch C, Oancea A, Orchard J (2015) The contribution of educational research to teachers' professional learning: philosophical understandings. Oxf Rev Educ 41:202-216

Wolff C (2015) Revisiting 'withitness': differences in teachers' representations, perceptions, and interpretations of classroom management. Dissertation, Open University of the Netherlands

Publisher's Note Springer Nature remains neutral with regard to jurisdictional claims in published maps and institutional affiliations.

\section{Affiliations}

\section{Gerbert Sipman $^{1,2} \cdot$ Jürg Thölke ${ }^{3} \cdot$ Rob Martens $^{4} \cdot$ Susan McKenney ${ }^{2}$}

1 HAN University of Applied Sciences, Ruitenberglaan 27, 6826 Arnhem, CC, the Netherlands

2 University of Twente, Postbox 217, 7500 Enschede, AE, the Netherlands

3 InHolland University of Applied Sciences, Wildenborch 6, 1110 Diemen, AG, the Netherlands

4 Open University of the Netherlands, Valkenburgerweg 177, 6419 Heerlen, AT, the Netherlands 